\title{
PENGELOLAAN PENGAMANAN PERBATASAN INDONESIA
}

Disusun untuk memenuhi tugas matakuliah Geografi Politik yang diampu oleh Dosen : Roni Alim Ba'diyah Kusufa, S.Pd., M.Pd.

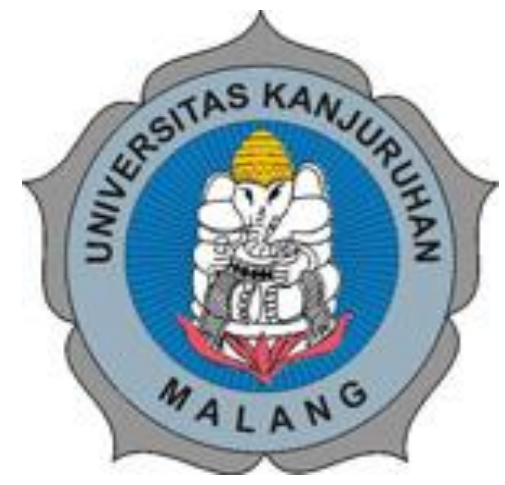

OLEH :

\section{LEONARDUS FIRMANSI TANGGUR}

150401050186

2016 C

UNIVERSITAS KANJURUHAN MALANG

FAKULTAS ILMU PENDIDIKAN PROGRAM STUDI PENDIDIKAN GEOGRAFI 2019 


\section{BAB I}

\section{PENDAHULUAN}

\subsection{Latar Belakang}

Upaya dan pengamanan wilayah perbatasan, baik laut maupun darat, masih menjadi permasalahan yang belum dapat terselesaikan secara tuntas. Kompleksitas permasalahan yang ada memosisikan pemerintah Indonesia harus secara tanggap dan eksplisit dalam pengamanan wilayahnya. Ada lima pokok yang menjadi tumpuan bagi pengelolaan pengamanan perbatasan sebagai beranda terdepan Indonesia, yakni manajemen, kedaulatan (Sukadis, Beni 2009), aktivitas ekonomi, identitas nasional, dan partisipasi pemerintah daerah setempat (Almanak Reformasi Sektor Keamanan Indonesia 2009).

Pada konteks yang terkait dengan manajemen pengelolaan perbatasan lebih menitikberatkan pada kegiatan lintas batas. Sementara pada konteks kedaulatan, ditegaskan bahwa perbatasan Negara menjadi cermin dari berdaulat tidaknya sebuah bangsa. Sedangkan pokok terkait dengan kegiatan ekonomi, lebih menitikberatkan adanya aktivitas legal maupun illegal yang menggunakan perbatasan negara sebagai media dalam melakukan transaksi ekonomi seperti pembalakan liar, pencurian ikan, dan lain sebagainya (World Customs Organization, 2006). Pada pokok identitas nasional kerap kali perbatasan menjadi beranda depan sebuah Negara, dimana baik tidaknya identitas sebuah Negara dapat dilihat dari baik tidaknya pengelolaan perbatasan. Dan yang terakhir adalah keterlibatan pemerintah daerah (Pemda) dalam pengamanan perbatasan, meski apabila dikaitkan dengan perundang-undangan masalah keamanan menjadi domain pemerintah pusat (UU No. 32/2004 tentang Pemerintahan Daerah). Namun partisipasi aktif Pemda menjadi bagian penting dari pengelolaan keamanan perbatasan.

Permasalahan perbatasan tidak hanya bersumber pada upaya lemahnya pengelolaan perbatasan, tapi juga lebih mendasar lagi dimana masalah delimitasi dan demarkasi yang masih dalam proses negoisasi (Aditya dan Beni Sukadis, 2007). Ada sembilan titik perbatasan yang belum terselesaikan dengan baik dengan Negara-negara seperti Singapura, Malaysia, Australia, Papua Nugini, 
Vietnam, India, Thailand, Timor Leste, dan Republik Palau (Kementerian Pertahanan Republik Indonesia, 2003). Permasalahan perbatasan dengan Philipina secara bilateral telah terselesaikan dengan baik. Selain itu banyak terjadi lihat UU No. 32/2004 tentang Pemerintahan Daerah, Pasal 10. 51 Aditya Batara. "Manajemen Perbatasan Indonesia: Upaya Menjamin Keamanan Manusia”, dalam Batara, Aditya dan Beni Sukadis (eds). (2007). Reformasi Manajemen Perbatasan dalam Transisi Demokrasi. Jakarta: Lesperssi-DCAF. Lihat juga Shiska. Ibid. Hal. 232 (Kementerian Pertahanan Republik Indonesia, 2003). Buku Putih Pertahanan. Jakarta: Kementerian Pertahanan RI. Hal. 24-5. Lihat juga Anak Agung Banyu Perwita. "Manajemen Perbatasan Negara dan Keamanan Nasional. dalam Sukadis, Beni. (ed). (2007). Almanak Reformasi Sektor Keamanan Indonesia 2007. Jakarta: Lesperssi-DCAF. Hal. 185 ketegangan terkait dengan masalah perbatasan dengan sejumlah Negara tersebut seperti yang terjadi pada blok Ambalat antara Indonesia dan Malaysia, atau juga ketegangan di Perbatasan antara Indonesia dan Timor Leste.

Tulisan ini akan mengupas bagaimana pengelolaan pengamanan perbatasan Indonesia. Dalam tulisan ini juga akan dibahas tentang perspektif pengelolaan pengamanan perbatasan, dan tulisan ini akan menguraikan pengelolaan pengamanan perbatasan dengan berbagai prasyarat pendukung nya, dengan men ga cu pada lima pokok pengelolaan perbatasan sebagaimana uraian tersebut di atas.

\subsection{Rumusan Masalah}

Berdasarkan latar belakang diatas dapat dirumuskan beberapa rumusan masalah sebagai berikut:

1. Bagaimana perspektif pengelolaan perbatasan?

2. Bagaimana pengamanan perbatasan negara?

\subsection{Tujuan Penulisan}

Tujuan penulisan makalah ini adalah :

1. Untuk mengetahui perspektif pengelolaan perbatasan.

2. Untuk mengetahui pengamanan perbatasan negara. 


\section{BAB II \\ PEMBAHASAN}

\subsection{Perspektif Pengelolaan Perbatasan}

Perbatasan antar-Negara adalah bagian dari penanda teritorial yang memisahkan Negara satu dengan Negara lain, yang dalam derajat tertentu dapat menjadi sumber konflik antar-Negara (Victor S. and Mary Ann Heiss 1995). Perbatasan antar- Negara juga menjadi penegas bahwa berdaulat atau tidaknya sebuah Negara dapat tercermin dalam bagaimana pengelolaan pengamanan perbatasannya. Situasi tersebut men syaratkan bahwa kesepakatan antara kedua negara atau lebih terkait dengan perbatasan menjadi penting bagi penge lolaan keamanan perbatasan masing-masing Negara. Sebab, jika tidak tercapai kesepakatan terkait dengan hal tersebut, masalah klaim perbatasan menjadi salah satu sumber konflik dan perang terbesar dalam sejarah peradaban manusia (Zacher, Mark W 2001).

Perbatasan antar-Negara ditetapkan melalui garis batas Negara, yakni sebuah garis imajiner yang merupakan bagian dari kesepakatan politik. Kesepakatan terkait dengan garis batas antar-Negara menjadi penting untuk menghindari ketegangan dan permasalahan dikemudian hari terkait dengan sistem internasional, dimana terdapat kepastian kedaulatan sebuah Negara berawal dan berakhir.

Sebagaimana ditegaskan oleh Stephen D. Jones terkait dengan ruang lingkup teritorial sebuah Negara terdiri dari alokasi, delimitasi, demarkasi, dan administrasi; maka sebuah Negara, termasuk Indonesia, dapat mengklaim wilayahnya dengan pendekatan empat hal tersebut dengan mengacu pada pewarisan wilayah Negara kolonial Hindia Belanda (Jones dalam Shiskha) Karakteristik Negara yang terbentuk karena warisan wilayah Negara kolonial membutuhkan penataan kenegaraan, khususnya pada pengelolaan wilayah perbatasan.

Mengacu pada lima hal pokok terkait dengan pengamanan perbatasan Indonesia, UU No. 43/2008 tentang Wilayah Negara dapat diterjemahkan secara positif bahwa pemerintah memiliki keseriusan dalam meng- koor dinasikan 
sistem pengamanan wilayah perbatasannya. Meski pada praktiknya, keberadaan UU tersebut selain tumpang-tindih, juga terkesan overlapping dengan berbagai produk perundang-undangan yang ada, khususnya terkait dengan pengelolaan keamanan wilayah perbatasan.

Beberapa produk perundang-undangan tersebut antara lain UU No. 6/1996 tentang Perairan, UU No. 2/2002 tentang Pertahanan Negara, UU No. 34/2004 tentang TNI, UU No. 31/2004 tentang Perikanan, UU No. 26/2007 tentang Penataan Ruang, UU No. 27/2007 tentang Pengelolaan Wilayah Pesisir dan Pulau Kecil, UU No. 17/2007 tentang Rencana Pembangunan Jangka Panjang Nasional 2005-2025, serta Perpres No. 81/2005 tentang Badan Koordinasi Keamanan laut, dan sebagainya.

Salah satu hal yang menonjol dari tumpang-tindih dan overlapping adalah tidak konsistennya pimpinan Komite Bersama Perbatasan antara satu wilayah dengan wilayah lain. Sekedar ilustrasi, misalnya perwakilan Indonesia dalam Komite Bersama Perbatasan Indonesia-Papua Nugini adalah Menteri Dalam Negeri, atau antara Indonesia-Malaysia diwakili oleh Menteri Pertahanan, dimana sebelum tahun 2004 dipimpin oleh Panglima TNI. Namun paska ter- bentuknya Badan Nasional Pengelola Perbatasan (BNPP) yang diketuai oleh Menteri Dalam Negeri, semua permasalahan perbatasan men jadi tanggung-jawab Kementerian Dalam Negeri dan sejumlah kement erian menjadi pendukung proses penanganan dan pengelolaan per batasan (Peraturan Menteri Dalam Negeri No. 2/2011).

Selain itu setidaknya ada empat permasalahan yang menjadi kendala dalam mengefektifkan pengamanan wilayah perbatasan, yakni: Pertama, semangat otonomi daerah yang pada kondisi penguatan demokrasi lokal relatif baik, namun pada pengembangan wilayah kedaulatan, pemerintah setempat melihat bahwa masalah pengamanan perbatasan adalah kewenangan pemerintah pusat. Situasi ini memosisikan masalah pengamanan perbatasan menjadi kurang baik dan cenderung terbengkalai (Undang-Undang Nomor 43 Tahun 2008).

Kedua, strategi dan postur pertahanan Indonesia masih pada visi teritorial, sehingga masalah perbatasan non-teritorial tidak terintegrasi dengan baik, karena minimnya Alutsista pendukung (Buku Putih Pertahanan tahun 2008). 
Ketiga, infrastruktur yang ada di wilayah perbatasan terbilang minim. Minimnya infrastruktur jalan dan pendukung lainnya menyulitkan Indonesia dalam melakukan pengamanan perbatasan secara luas. Konteks ini pada akhirnya membuat pengamanan wilayah perbatasan dilakukan terbatas dan cenderung seadanya.

Keempat, minimnya dukungan anggaran bagi pengamanan perbatasan secara efektif menyebabkan kinerja dan profesionalitas petugas di lapangan menjadi rendah. Kurangnya dukungan dan perhatian dari Pemda setempat juga menjadi masalah yang melemahkan pengamanan perbatasan.

Kelima, visi pengamanan yang berorientasi pada pendekatan militer semata menjadi permasalahan ter sendiri mengingat ancaman keamanan dan kedaulatan tidak lagi semata-mata berbentuk ancaman agresi militer, tapi lebih banyak pada ancaman non-tradisional yang justru merupakan bagan dari domain penegakan hukum (Buku Putih Pertahanan tahun 2008).

\subsection{Pengamanan Perbatasan Negara}

Berkaca pada uraian tersebut di atas, pengamanan perbatasan harus diarahkan untuk menstimulasi pengembangan dan mempercepat pembangunan wilayah perbatasan, dengan menselaraskan laju pertumbuhan ekonomi dan pembangunan wilayah perbatasan seperti daerah lainnya. Dalam konteks tersebut, pelaksanaannya harus disesuaikan dengan prioritas dan potensi daerah setempat sehingga selaras dengan pola pembangunan berWawasan Nusantara (Lembaga Ketahanan Nasional 1995).

Secara garis besar terdapat dua hal penting sebagai pondasi bagi pengamanan perbatasan, yakni pembangunan daerah perbatasan dengan pendekatan kesejahteraan guna meningkatkan kehidupan masyarakat setempat dan pendekatan keamanan agar terciptanya stabilitas politik, ekonomi, sosial budaya, dan pertahanan keamanan sehingga memungkinkan terwujudnya keserasian hidup berdampingan secara damai. Penggunaan dua pendekatan tersebut menjadi landasan dari hakikat dan tujuan program-program pembangunan di wilayah perbatasan secara terintegrasi dan berkelanjutan. 
Selain itu, arah pembangunan wilayah perbatasan diprioritaskan untuk memacu pemerataan pem- bangunan dan hasil-hasilnya guna mening katkan kesejahteraan, memper kuat prakarsa dan peran serta aktif masyarakat di wilayah perbatasan, serta pendayagunaan potensi daerah secara optimal dan terpadu sesuai semangat otonomi daerah tanpa mengurangi tanggung-jawab pada pengamanan perbatasan.

Karenanya, pembangunan wilayah perbatasan harus diarahkan untuk mengembangkan tata ruang wilayah perbatasan menjadi kawasan strategis dan potensial dalam rangka penataan tata ruang wilayah dengan memperhatikan pengamanan daerah perbatasan guna menjaga tetap tegaknya keutuhan dan kedaulatan negara.

Mengacu pada uraian tersebut di atas, maka pengelolaan perbatasan dapat dilakukan dengan cara: Pertama, meningkatkan pengawasan terhadap pencurian Sumber Daya Alam (SDA), seperti pencurian kayu, pencurian ikan dan kekayaan laut, eksplorasi energi dan mineral secara ilegal. Dalam banyak kasus, pencurian dilakukan dengan modus bekerja sama dengan masyarakat lokal setempat, yang tidak hanya merusak lingkungan, tapi juga menggeser patok perbatasan serta merugikan Negara milyaran rupiah. Selain itu, perlu juga dilakukan survei dan pemetaan secara terpadu bagi pengamanan terhadap SDA, jalur kejahatan transnasional dan area rawan konflik etnis di daerah perbatasan sebagai integrated data base pengamanan perbatasan negara.

Kedua, meningkatkan koordinasi antar-instansi pemerintah yang terkait dalam pengamanan wilayah perbatasan seperti TNI, Polri, Kantor Imigrasi Kementerian Hukum dan HAM, Kementerian Kehutanan, Kementerian Kelautan dan Perikanan, Kementerian Energi Sumber Daya Mineral, Kementerian Pertanian dan Pemerintah Daerah.

Ketiga, mengupayakan pening- katan kualitas pengawasan di pos-pos lintas batas terhadap lalu lintas barang dan orang. Peningkatan pengawasan meliputi penambahan pos-pos pengawasan dan personil di pos lintas batas. Dalam kon teks ini sesungguhnya upaya untuk meningkatkan kualitas pos-pos lintas batas juga harus dibarengi oleh peningkatan kualitas kesejahteraan petugas jaga dan masyarakat di sekitar perbatasan. 
Keempat, meningkatkan dan mem bangun jaringan intelijen secara terpadu di daerah perbatasan untuk mengantisipasi kemungkinan penyelundupan barang, senjata api dan amunisi serta narkoba, dan penyusupan teroris dan adanya oknum yang dapat memicu konflik antar etnis. Keberadaan Komunitas Intelijen Daerah (Kominda), dan kemudian struktur BIN yang berada hingga di daerah harus menjadi penguat bagi kinerja intelijen secara umum guna mengkondisikan pengamanan perbatasan lebih baik lagi. Pada konteks ini sesungguhnya mengedepankan deteksi dini dan pendekatan militer sangat mungkin dilakukan, sebab menata pengamanan perbatasan juga selain dalam konteks penegakan hukum juga utamanya adalah dengan memperkuat deteksi dini guna meminimalisir ancaman kedaulatan di perbatasan.

Kelima, mengupayakan dan mening katkan pembinaan wilayah, pembinaan teritorial serta pembinaan masyarakat di wilayah perbatasan. Langkah ini dilakukan agar terjadi harmonisasi dan koordinasi yang efektif antar-instansi dan mengintegrasikannya bagi pengamanan perbatasan secara integral. Penguatan potensi pertahanan dan militer dapat dilakukan khusus di wilayah perbatasan. Hal ini salah satunya direspon oleh pimpinan Kementerian Pertahanan dan Mabes TNI dengan meningkatkan status Komando Resor Militer dari sebelumnya dipimpin oleh perwira menengah berpangkat kolonel menjadi dipimpin oleh perwira tinggi bintang satu. Keenam, membangun jalan inspeksi di sepanjang perbatasan darat dan menambah frekwensi patroli perbatasan di darat maupun laut. Intensivitas dan dukungan infrastruktur yang baik adalah bagian dari bagaimana menjaga komitmen atas setiap jengkal wilayah kedaulatan Indonesia.

Ketujuh, menambah dan mening- katkan kuantitas dan kualitas alat peralatan pengamanan di daerah perbatasan, seperti radar, navigasi, alkom, jarkom, kendaraan patrol, dan alutsista. Medan yang sulit dan peralatan yang minim menjadi bagian permasalahan tidak efektifnya pengelolaan pengamanan perbatasan. Sehingga untuk mengefek tifkan dan meminimalkan hal tersebut harus ditopang oleh kuantitas dan kualitas peralatan yang baik.

Kedelapan, mengalokasikan anggaran pengamanan daerah perbatasan secara terpadu. Belum maksimalnya pengelolaan pengamanan perbatasan disinyalir karena penganggaran terkait dengan hal tersebut masih bersifat sektoral. 
Dalam konteks ini sesungguhnya keberadaan sejumlah personil dari berbeda instansi akan lebih efektif apabila penganggarannya disatukan pada satu pos yang mana mencakup instansi-instasi tersebut dalam keterpaduan irama yang sama dalam pengamanan perbatasan. Konsekuensi dari itu adalah merealisasikan terbentuknya suatu badan atau lembaga pengamanan daer ah perbatasan secara terpadu dalam rangka meningkatkan pengawasan dan pengendalian segala bentuk kejahatan dan konflik yang mungkin terjadi di daerah perbatasan.

Sembilan, selain itu, membangun sarana jalan dan prasarana transportasi dan telekomunikasi sepanjang perbatasan untuk membuka keterisolasian wilayah perbatasan. Sarana dan prasarana yang ada bukan hanya memberikan kemud ahan bagi petugas dalam pengamanan perbatasan, tapi juga menstimulasi peran serta masyarakat dalam pengamanan wilayah negaranya. Dalam konteks ini peran Pemda menjadi sangat signifikan dan penting. Sepuluh, mengintegrasikan dan/ atau merevisi peraturan dan perundangan yang terkait dengan pengamanan daerah perbatasan, baik yang menyangkut pen curian, penyelundupan, dan penyusupan serta kejahatan transnasional lainnya demi terwujudnya penegakan dan ke pastian hukum di daerah perbatasan maupun yang bersifat perjanjian antar kedua Negara. 


\section{BAB III \\ PENUTUP}

\subsection{Kesimpulan}

1. Pengelolaan pengamanan perbatasan secara harfiah membutuhkan prasyarat dan pranata bagi efektivitas pengamanannya. Akan hal tersebut, pengamanan terintegrasi dalam satu institusi tersendiri dapat memberikan sinyalemen kesuksesan. Berkaca pada hal tersebut, pengelolaan pengamanan perbatasan juga harus ditopang oleh diplomasi dan penegasan-penegasan sikap pemerintah terkait dengan perbatasan dan wilayah yang menjadi bagian dari kedaulatan Negara.

2. Perlu juga digarisbawahi bahwa keterlibatan aktif Pemda dan masyarakat setempat dapat memudahk an pengelolaan pengamanan perbatasan secara efektif dan berkesinambungan. Dimana bukan saja dukungan finasial semata, tapi juga sarana pendukung bagi suksesnya pengamanan perbatasan tersebut. Dengan begitu akan lebih mudah mengimplementasikan penge- lolaan pengamanan secara efektif.

\subsection{Saran}

Saran yang direkomendasikan oleh penulis adalah :

1. Bagi teman-teman sejawat kiranya dapat memahami dan mengerti materi yang telah disampaikan penulis agar bisa menjadi bekal dalam bidang penelitian nantinya.

2. Bagi para peneliti lanjutan, diharapkan untuk menambah sumber buku agar dapat membandingkan teori-teori yang dikemukakan guna menambah pengetahuan bagi peneliti dan pembaca. 


\section{DAFTAR PUSTAKA}

Batara, Aditya. 2007. "Manajemen Perbatasan Indonesia: Upaya Menjamin Keamanan Manusia”, dalam Aditya Batara dan Beni Sukadis (eds). Reformasi Manajemen Perbatasan dalam Transisi Demokrasi. Jakarta: Lesperssi-DCAF.

Alden, Edward, 2008. The Closing of American Border: Terrorism, Immigration, and Security Since 9/11. New York: Harper Parennial.

Andreas, Peter, 2009. Border Games: Policing the US-Mexico Divide. New York: Cornell University.

Bowman, G.W., 2006, 'Thinking Outside the Border: Homeland Security and the Forward Deploy- ment of the US Border', Houston Law Review, vol. 44, no. 2 .

Kementerian Pertahanan Republik Indonesia, 2008. Buku Putih Pertahanan. Jakarta: Kementerian Pertahanan RI.

Lembaga Ketahanan Nasional, 1995. Wawasan Nusantara. Jakarta: Balai Pustaka. Maria, Polner, 2003. "Coordinated Border Management: From Theory to Practice". World Cos- tums Journal, Volume 5, No. 2. Mitsilegas, V.,

Monar, J \& Rees, W., 2003. The European Union and International Security, Guardian of the People? London: Palgrave Macmillan.

Moeldoko, 2011. "Kompleksitas Pengelolaan Perbatasan: Tinjauan dari Perspektif Kebijakan Pe- ngelolaan Perbatasan Indonesia.” Jakarta: Universitas Pertahanan Indonesia.

Nugroho, Ryant, 2011. "Defense Border Policy: Ten Years of Indonesia Policy Defense Border Developments in Preserving Peace, Security, and Political Integration". Jakarta: Universitas Pertahanan Indonesia.

Perwita, Anak Agung Banyu, 2007. "Manajemen Perbatasan Negara dan Keamanan Nasional" dalam Beni Sukadis (ed). Almanak Reformasi Sektor Keamanan Indonesia. Jakarta: Lesperssi- DCAF. 
Prabawaningtyas, Shiska, 2009. "Diplomasi Bertetangga Baik dan Penegakan Hukum dalam Manajemen Perbatasan” dalam Beni Sukadis (ed). Almanak Reformasi Sektor Keamanan Indonesia. Jakarta: Lesperssi- DCAF. Sutisna, Sobar, 2011. "Pengamanan Wilayah Perbatasan Negara Kesatuan Republik Indonesia dan Kepastian Hukum bagi Pertahanan wilayah Negara”. Jakarta: Universitas Pertahanan Indonesia.

Yani, Yanyan Muhamad, 2008. "Pengamanan Wilayah Perbatasan Darat Guna Mendukung Keutuhan Negara Kesatuan Republik Indonesia”, Disampaikan pada acara Roundtable Discussion "Meningkatkan Pe- ngamanan Wilayah Perbatasan Darat Guna Mendukung Pem- bangunan Nasional Dalam Rangka Menjaga Keutuhan NKRI”. Jakarta: LEMHANAS RI, 11 Nopember 2008.

Victor S. and Mary Ann Heiss (eds), 1995. NATO in the Post Cold War Era: Does it Have A Future? New York: Palgrave Macmillan.

World Customs Organization, 2006. Integrated Border Management. Brussels: World Customs Organization. 